\title{
criação
}

\section{O Corpo e a Saúde}

The Body and Health

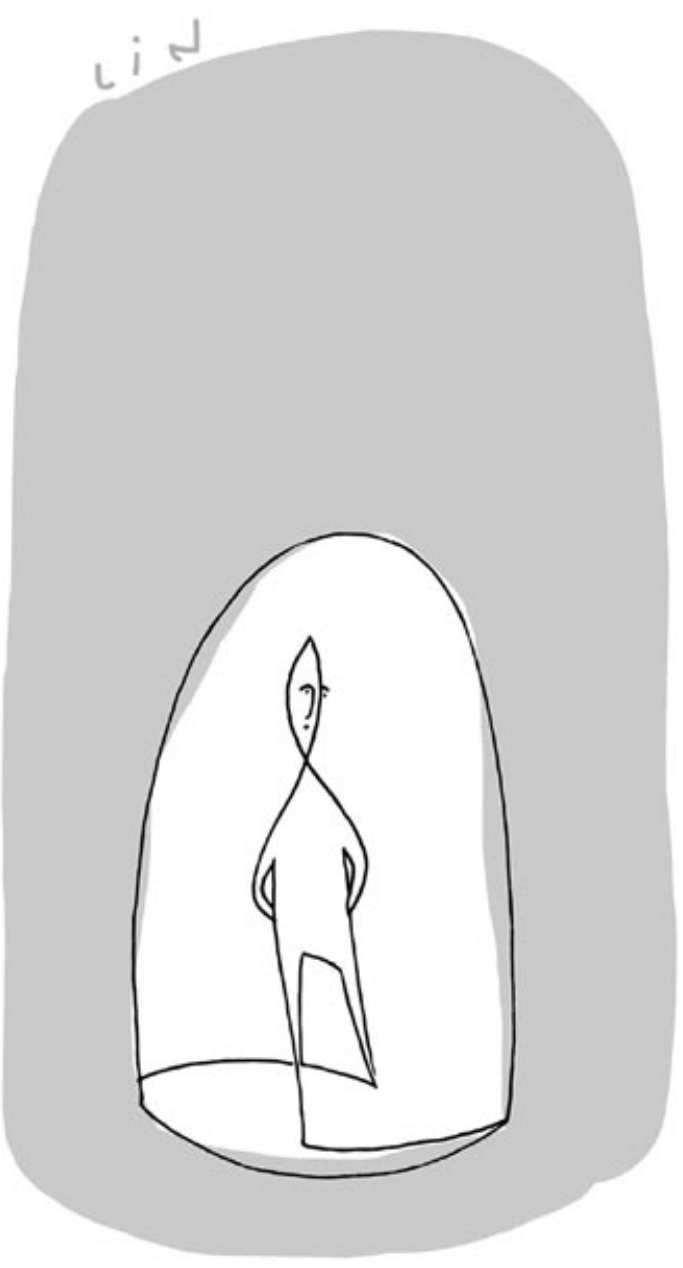




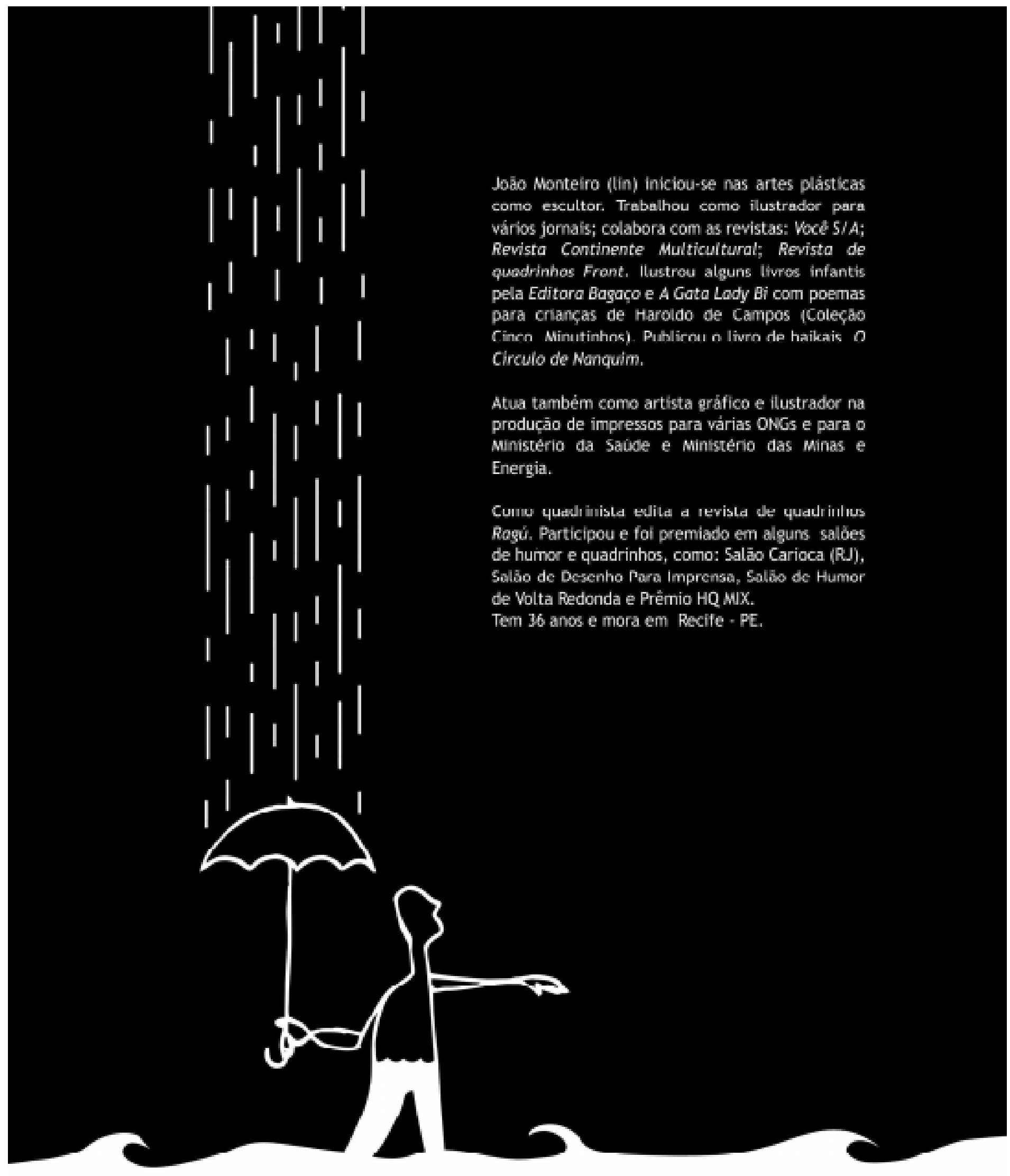




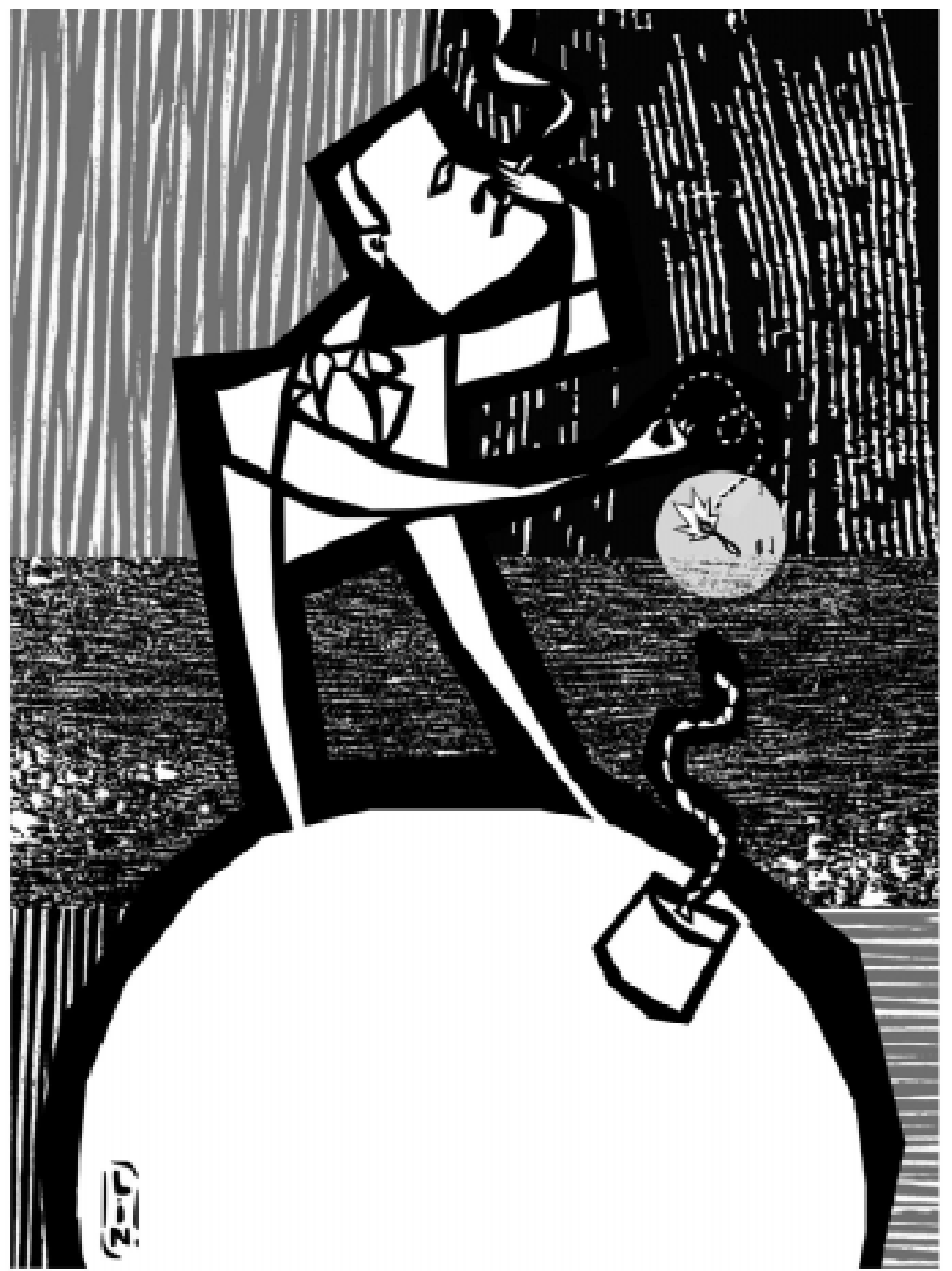


CRIAÇÃO
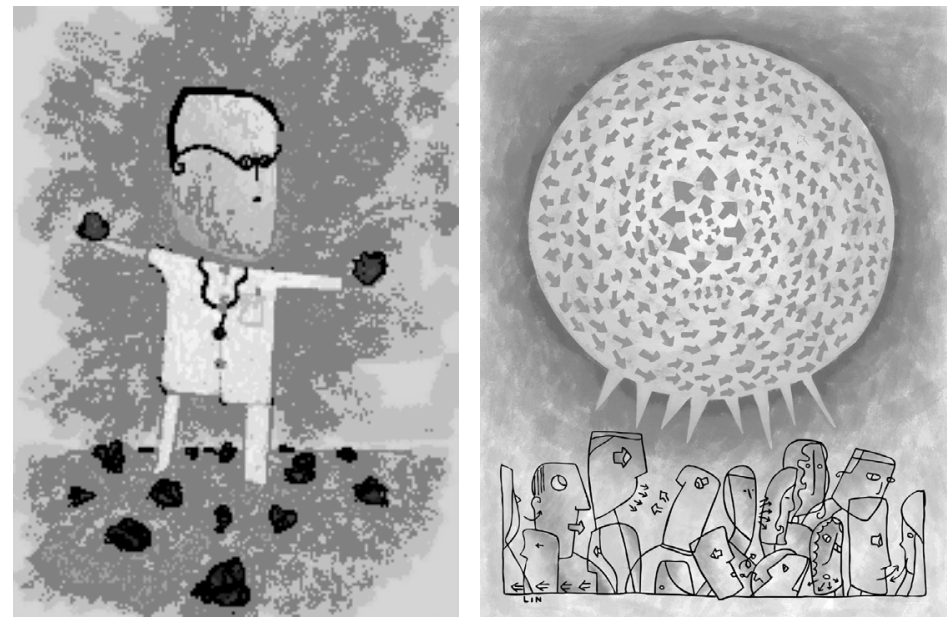

206 Interface - Comunic., Saúde, Educ., v.8, n.14, p.203-6, set.2003-fev.2004 